\title{
STUDI TENTANG KINERJA MESIN DAIHATSU GRAN MAX 1300 YANG MENGGUNAKAN PREMIUM DAN BAHAN BAKAR GAS (BBG)
}

\author{
Audri D. Cappenberg \\ Jurusan Teknik Mesin Universitas 17 Agustus 1945 Jakarta \\ e-mai : audri.cappenberg@uta45jakarta.ac.id
}

\begin{abstract}
ABSTRAK
Ketersediaan bahan bakar Fosil (BBM) semakin berkurang, sementara ketergantungan terhadap BBM sebagai bahan bakar untuk kendaraan semakin meningkat. Disamping dampak lingkungan yang diakibatkan oleh polutan yang dihasilkan kendaraan semakin meningkat dan berakibat pada tingkat pencemaran lingkungan tinggi, maka pemerintah DKI Jakarta menetapkan aturan untuk penggunaan BBG sebagai bahan bakar untuk kendaran operasional pemerintah dan kendaraan umum. Penggunaan BBG sebagai bahan bakar akan lebih baik, karena pembakaran didalam motor akan menjadi lebih sempurna dan harga BBG yang cukup murah.

Untuk itu dilakukan studi tentang penggunaan BBG pada kendaraan umum, khususnya kendaraan tipe gran max 1300CC, yang banyak digunakan sebagai kendaraan angkutan umum. Hasil uji coba menunjukkan bahwa daya dan torsi pada penggunaan premium lebih besar dari yang menggunakan $C N G$, demikian juga untuk hasil perhitungan; pada penggunaan premium, putaran mesin $4100 \mathrm{rpm}$ daya 44,45 W dan torsi 105,50 Nm; pada penggunaan CNG, untuk putaran yang sama, daya 42,18 dan torsi $101.2 \mathrm{Nm}$
\end{abstract}

Kata kunci : CNG, premium, daya dan torsi

\section{PENDAHULUAN}

Penggunaan kendaraan bermotor roda empat dari waktu ke waktu terus meningkat, sampai dengan tahun 2014, dari kantor Kepolisian RI didapatkan data berikut : jumlah kendaraan roda empat yang beroperasi di wilayah jakarta dan sekitarnya mencapai \pm 4.1 juta unit $(25.46 \%$ dari jumlah kendaraan di Jakarta) dan jumlah mobil penumpang \pm 360.000 unit. Peningkatan populasi kendaraan akan diikuti dengan konsumsi bahan bakar yang meningkat pula, dalam hal ini solar, bensin dan sejenisnya. Sementara saat ini ketersediaan bahan bakar minyak (BBM) semakin menipis, diprediksikan dalam kurun waktu \pm 30 tahun, bahkan ada pakar yang memprediksi dalam waktu belasan tahun ketersediaan minyak akan habis.

Untuk itu ketergantungan terhadap BBM harus dialihkan pada sumber energy alternatif lainnya, misalnya gas .

Indonesia memiliki cadangan gas yang cukup besar, \pm 104.37 TFC (triliun cubic feet); sumber US Energy Information Administrasion, 5 Maret 2014.Peringkat 13 di dunia yang memiliki cadangan gas alam terbesar, dan peringkat kedua di Asia Pasifik.Indonesia juga mengekspor gas dalam bentuk LNG.

Berdasarkan hal tersebut, maka penggunaan gas sebagai bahan bakar kendaraan sudah harus dilaksanakan.
Sesungguhnya penggunaan BBG untuk kendaraan sudah telah diperkenalkan sejak tahun 1986, dan saat itu banyak taksi yang telah menggunakan CNG (compressed natural gas) sebagai bahan bakar, bahkan secara nasional pemerintah telah mencanangkan konversi BBM ke BBG beberapa tahun yang lalu.

Pemerintah DKI Jakarta lewat Peraturan Gubernur No. 141 Tahun 2007, tentang penggunaan BBG untuk angkutan umum dan kendaraan operasional Pemda, turut menunjang percepatan konversi BBM ke BBG.

Untuk mengurangi ketergantungan terhadap BBM, serta mengatasi tingginya beban subsidi pemerintah terhadap bahan bakar, maka pemerintah mengeluarkan Peraturan Presiden RI No. 64 tahun 2012, tentang Penyediaan, Pendistribusian dan Penetapan Harga BBG untuk Transportasi Jalan.

Implementasi dari peraturan tersebut adalah dibangunnya SPBG di beberapa wilayah, namun sampai dengan saat ini belum terlasana secara optimal.

Sampai dengan saat ini penggunaan BBG masih sangat rendah, sementara kendaraan yang ada maupun yang baru diproduksi masih banyak yang menggunakan bahan bakar premium dan sejenisnya.

Untuk kendaraan yang menggunakan bahan bakar bansin ataupun solar, bila akan menggunakan BBG, maka harus menggunakan konveter kit. Saat ini sudah banyak converter kit yang tersedia di pasaran. 
Penggunaan BBG pada kendaraan bermotor akan sangat bermanfaat dari sisi efisiensi bahan bakar, lebih bersih dan harga lebih murah . Selain itu penggunaan BBG juga akan mengurangi tingkat pencemaran udara yang semakin tinggi.

Khusus untuk transpotasi umum di Jakarta, pemerintah telah menetapkan untuk penggunaan BBG sebagai bahan bakar menggantikan BBM

Di lapangan masih banyak kendaraan umum yang menggunakan BBM, karena sejak awal beroperasi telah menggunakan BBM, dan BBM mudah didapat, mungkin juga para pemilik kendaraan belum memahami tentang konversi BBM ke BBG dan berbagai keuntungan bila menggunakan BBG pada kendaraannya, untuk itu perlu dianalisa kinerja maupun konstruksi dari kendaraan ketika menggunakan BBG.

\section{TUJUAN}

- 1. analisa kinerja mesin daihatsu Grand Max 1300 cc yang menggunakan premium dan BBG

- 2. analisa konstruksi mesin jika menggunakan $\mathrm{BBG}$

- 3. memberikan pemahaman bahwa konversi BBM ke BBG merupakan salah satu cara untuk mewujudkan Ketahanan Energi Nasional

\section{TEORI DASAR}

\subsection{Umum}

Mobil Daihatsu Gran Max yang diaplikasikan untuk kendaraan angkutan umum, merupakan kendaraan bermotor yang menerapkan sistem BI-Fuel; yaitu system yang menggunakan bahan bakar premium dan gas secara bergantian (lihat gambar 1). Mesin yang digunakan sama dengan yang digunakan untuk bahan bakar premium, hanya memerlukan peralatan tambahan yaitu Converter Kit.

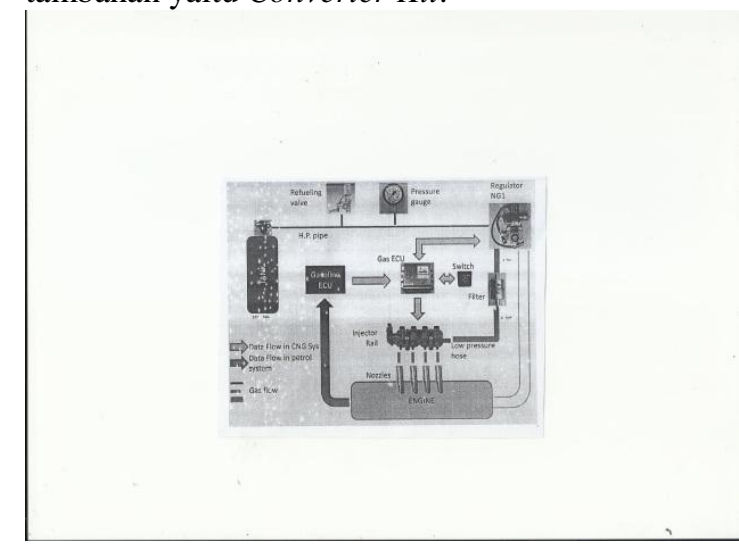

BBG (CNG) yang memiliki tekanan 300 bar, berasal dari stasiun pengisian bahan bakar
(SPBG), dimasukkan dan dikompresikan kedalam silinder (CNG Cylinder tank) melalui fill up valve

Tekanan maksimal yang diijinkan dalam silinder adalah 248 bar dan tekanan operasional 200 bar. Daihatsu Gran Max berbahan bakar gas menggunakan tanki berkapasitas $80 \mathrm{sl}$. CNG dalam silinder mengalir melalui katup silinder dengan tekanan 200 bar. Katup silinder mengatur waktu keluar CNG dan menutup secara otomatis bila terjadi kebocoran pada silinder.

CNG yang keluar dari silinder, masuk ke pengukur tekanan (pressure gauge) untuk dicheck tekanannya (200 bar)selanjutnya mengalir ke regulator ; tekanan diturunkan (2 bar), kemudian mengalir ke common rail gas injector.

Daihatsu Gran Max yang merupakan kendaraan uji ini menggunakan 2 tipe bahan bakar, yaitu premium dan gas. Bila kendaraan akan menggunakan BBG/CNG, maka emulator akan mengisntruksikan ECU untuk mengatur kerja dari common rail gas injector yang akan mengalirkan CNG ke injector hose dan injector gas menuju cylinder head, maka terjadilah proses pembakaran.

Bila akan menggunakan premium, maka emulator akan menginstruksikan ECU untuk gasoline mengatur premium yang akan masuk ke cylinder head dan terjadi pembakaran.

3.2. Penggunaan Premium sebagai bahan bakar Daihatsu Gran Max 1300 cc menggunakan premium sebagai bahan bakar. Premium yang digunakan memiliki nilai oktan $88(88 \%$ oktan dan $12 \%$ heptana/campuran molekul lainnya).Oktana $\left(\mathrm{C}_{8} \mathrm{H}_{18}\right)$ merupakan salah satu unsure penyusun bensin yang memiliki sifat kompresi yang sangat baik; dapat dikompresikan sampai volume kecil tanpa pembakaran spontan.

3.3. Penggunaan $\mathrm{CNG}$ sebagai bahan bakar CNG adalah gas alam yang dikompresikan sehingga volumenya hanya $1 \%$ dari volume standar dengan tekanan atmosfir. CNG disimpan dalam tekanan tinggi (200 - 220 bar). CNG lebih ringan dari pada udara, sehingga penguapan lebih cepat saat terjadi kebocoran.

Daihatsu Gran Max 1300 cc juga menggunakan gas sebagai bahan bakar. Susunan molekul BBG terdiri dari Hidrogen dan Carbon.BBG yang diguanakan adalah jenis CNG (Compressed Natural Gas) dengan 
angka oktan 94.Pada BBG tidak diberi zat aditif untuk meningkatkan nilai oktannya.Komposisi utama dari CNG adalah metana $\left(\mathrm{CH}_{4}\right)$.Tekanan yang dihasilkan CNG adalah 200 bar. Penggunaan CNG cukup aman, karena instalasi dilengkapi dengan bursting disc disetiap katup silinder, tes tekanan hingga 300 bar dan burst test cylinder yang harus dilakukan minimal 450 bar. transJakarta, bajaj BBG dan mikrolet BBG menggunakan CNG.

Alasan pemilihan CNG sebagai bahan - bakar Daihatsu Gran Max adalah sebagai berikut :

- Harga murah, bila dibandingkan dengan jenis lainnya dan juga dengan BBM

- Banyak digunakan oleh moda transportasi lainnya: TransJakarta dan taksi

- Potensi CNG di Indonesia cukup banyak

- Berasal dari gas alam bukan minyak mentah (light sweet)

- Dalam upaya mendukung dan mewujudkan Ketahanan energi Nasional, maka Pertamina meluncurkan Envogas, dan TNI telah memanfaatkannya sebagai bahan bakar operasional di lingkungan TNI (lebih dari 500 kendaraan)

Populasi kendaraan di wilayah Jakarta dan sekitarnya yang berbahan bakar minyak (BBM) tiap tahun terus meningkat, dengan demikian akan berdampak pada polusi udara dan pencemaran lingkungan, disamping ketersediaan BBM yang mulai terbatas

- Solusi dari masalah tersebut adalah bahan bakar alternatif, salah satu diantaranya adalah bahan bakar gas (BBG)

- Konversi BBM ke BBG pada kendaraan masih banyak masalah; Indonesia Energi Monitoring (Indering) menyampaikan masalah tersebut adalah :

- Belum ada kuota pasokan gas untuk transpotasi
- Gas yang digunakan belum berkualitas
- Spare part untuk peralatan konversi belum tersedia
- standar yang digunakan untuk peralatan konversi belum lengkap - belum ada lembaga yang menguji peralatan konversi

-SDM yang menangani instalasi converter kits masih terbatas

Kepala dinas Perhubungan DKI Jakarta menyampaikan bahwa program penggunaan BBG untuk kendaraan operasional untuk sementara dihentikan, karena SPBG belum ada

- Jika ada masyarakat yang akan menggunakan bbg, pemda beserta dinas perindustrian dan energi akan membantu mendistribusikan converter kits

\section{METODOLOGI PENELITIAN}

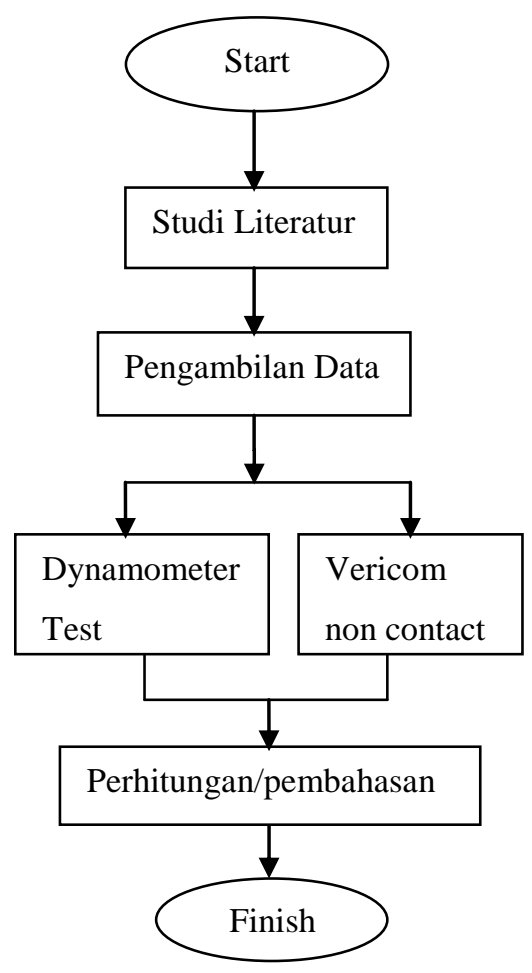

Gambar 4.1 Diagram alir penelitian 


\section{ANALISA DAN PEMBAHASAN}

\subsection{Analisa dan Pengolahan Data}

\subsubsection{Data hasil pengujian}

Data hasil pengujian dynamometer test untuk Daya dan Torsi termuat pada table berikut

Tabel 5.1. Hasil pengujian

\begin{tabular}{|l|l|l|l|l|}
\hline \multirow{2}{*}{ RPM } & \multicolumn{2}{|c|}{ CNG } & \multicolumn{2}{c|}{ Premium } \\
\cline { 2 - 5 } & $\begin{array}{l}\text { Daya } \\
\text { (W) }\end{array}$ & $\begin{array}{l}\text { Torsi } \\
(\mathrm{Nm})\end{array}$ & $\begin{array}{l}\text { Daya } \\
(\mathrm{W})\end{array}$ & $\begin{array}{l}\text { Torsi } \\
(\mathrm{Nm})\end{array}$ \\
\hline 2400 & 22.54 & 89.62 & 23.23 & 92.47 \\
\hline 2800 & 27.66 & 94.64 & 28.41 & 97.62 \\
\hline 3100 & 31.39 & 97.62 & 32.3 & 100.3 \\
\hline 3300 & 33.04 & 95.18 & 34.74 & 101.1 \\
\hline 3600 & 36.60 & 96.94 & 38.42 & 102.8 \\
\hline 4100 & 41.71 & 99.96 & 44.1 & 103.6 \\
\hline 4400 & 47.39 & 102.8 & 48.59 & 106.0 \\
\hline 4440 & 47.99 & 103.0 & 49.63 & 106.8 \\
\hline 5180 & 52.92 & 97.35 & 53.82 & 98.70 \\
\hline 5920 & 53.82 & 82.23 & 53.07 & 85.15 \\
\hline
\end{tabular}

Data yang ditampilkan adalah yang diambil dari titik tertentu untuk mempermudah analisa.

Dari table 5.1 terlihat bahwa torsi untuk kendaraan yang menggunakan premium lebih besar dari yang menggunakan bahan bakar gas (CNG). Torsi maksimum untuk bahan bakar premium adalah $106.8 \mathrm{Nm}$ pada putaran 4440 rpm, dan untuk bahan bakar gas (CNG) torsi maksimum pada putaran $4440 \mathrm{rpm}$, yaitu 103.0 Nm.

Demikian pula untuk hasil pengujian daya, , untuk bahan bakar gas (CNG) daya maksimum adalah $53.82 \mathrm{~W}$, pada putaran $5920 \mathrm{rpm}$, sedangkan untuk kendaraan yang berbahan bakar premium daya maksimum adalah 53.82 $\mathrm{W}$, pada putaran $5180 \mathrm{rpm}$.

\subsubsection{Data hasil perhitungan}

Berdasarkan data hasil uji pada table 5.1, maka dibuat perhitungan secara matematis dengan menggunakan persamaan berikut :

$$
\mathrm{P}=\mathrm{F} . \mathrm{V}
$$

Keterangan :

$\mathrm{P}$ : daya $(\mathrm{W})$

$\mathrm{F}$ : gaya $(\mathrm{N})$;

$\mathrm{V}:$ kecepatan $(\mathrm{m} / \mathrm{s}) ; \mathrm{v}=\mathrm{r} . \omega$

Hasil perhitungan berdasarkan data pada ditampilkan pada table berikut :
Tabel 5.2 Hasil Perhitungan Daya dan Torsi

\begin{tabular}{|l|l|l|l|l|}
\hline \multirow{2}{*}{ RPM } & \multicolumn{2}{|c|}{ CNG } & \multicolumn{2}{c|}{ Premium } \\
\cline { 2 - 5 } & $\begin{array}{l}\text { Daya } \\
(\mathrm{W})\end{array}$ & $\begin{array}{l}\text { Torsi } \\
(\mathrm{Nm})\end{array}$ & $\begin{array}{l}\text { Daya } \\
(\mathrm{W})\end{array}$ & $\begin{array}{l}\text { Torsi } \\
(\mathrm{Nm})\end{array}$ \\
\hline 2400 & 22.54 & 89.62 & 23.23 & 92.47 \\
\hline 2800 & 27.77 & 94.64 & 28.61 & 97.62 \\
\hline 3100 & 31.72 & 97.62 & 32.55 & 100.33 \\
\hline 3300 & 32.92 & 99.18 & 34.94 & 101.14 \\
\hline 3600 & 36.58 & 100.1 & 38.72 & 102.77 \\
\hline 4100 & 42.18 & 101.2 & 44.45 & 105.58 \\
\hline 4400 & 47.39 & 102.8 & 48.83 & 106.03 \\
\hline 4440 & 47.95 & 103.0 & 49.65 & 106.84 \\
\hline 5180 & 52.85 & 97.35 & 53.51 & 98.70 \\
\hline 5920 & 53.50 & 86.23 & 52.76 & 85.15 \\
\hline
\end{tabular}

Dari hasil perhitungan secara matematis, menunjukkan bahwa daya yang dihasilkan untuk kendaraan berbahan bakar premium lebih besar bila dibandingkan dengan daya yang dihasilkan oleh kendaraan dengan bahan bakar gas $(\mathrm{CNG})$, karena torsi yang dihasilkan yaitu lebih besar torsi kendaraan yang menggunakan premium bila dibandingkan dengan yang menggunakan gas.

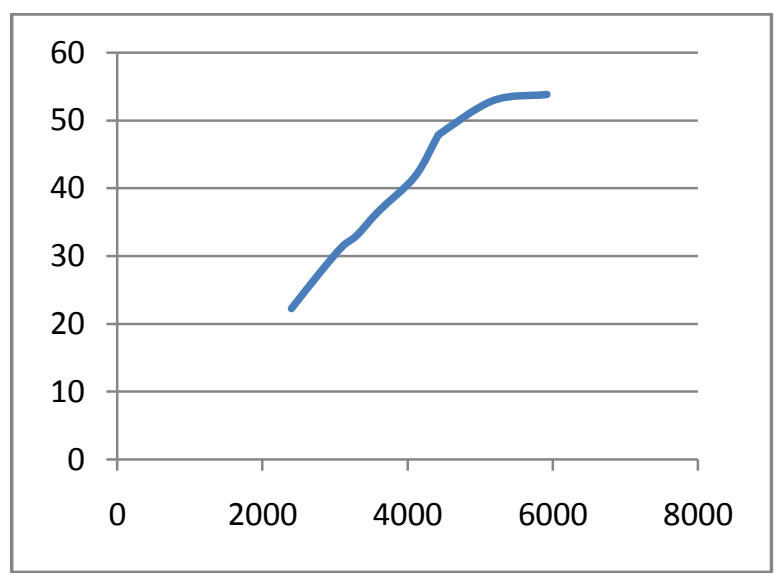

Grafik 1a. RPM vs Daya untuk CNG 


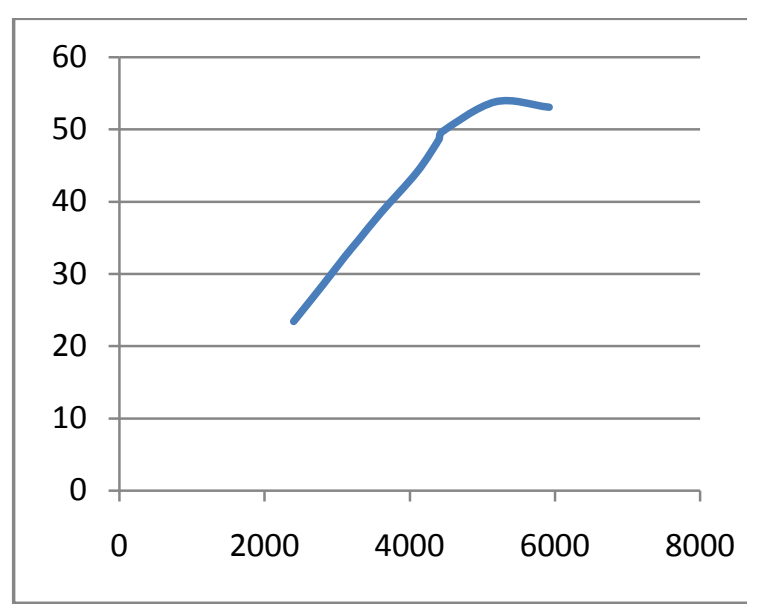

Grafik 1b. RPM vs Daya untuk Premium

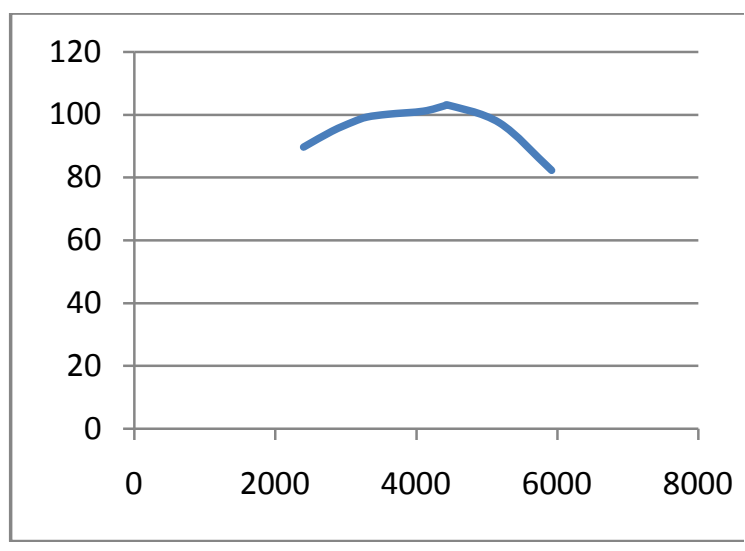

Grafik 2a. RPM vs Torsi untuk CNG

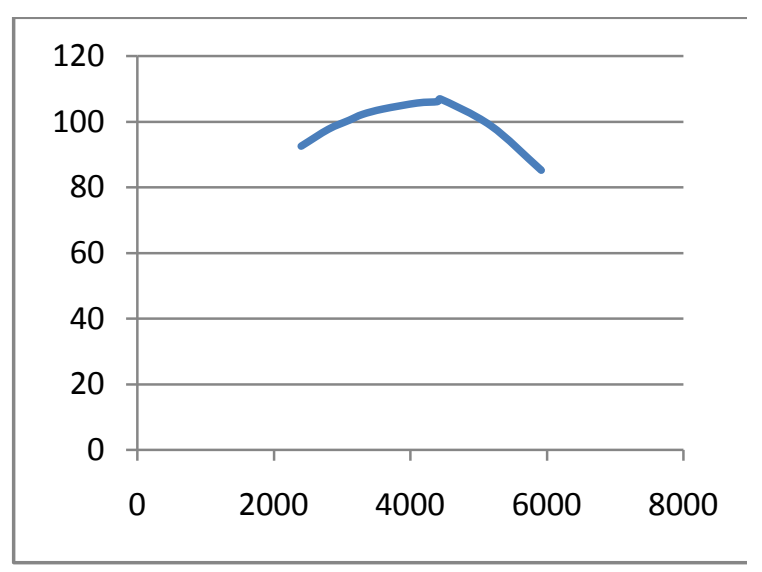

Grafik 2b. RPM vs Torsi untuk Premium

Daya yang dihasilkan oleh sebuah mesin, sangat dipengaruhi oleh torsi yang dihasilkan, ketika kompresi bahan bakar di ruang bakar.Nilai kompresi bahan bakar bergantung pada nilai oktan suatu bahan bakar. Makin tinggi nilai oktan suatu bahan bakar akan berpengaruh pada torsi yang dihasilkan. Dalam hal ini untuk bahan bakar premium memiliki nilai oktan 88 dan dan bahan bakar gas (CNG) oktannya 94, dengan demikian seharusnya kendaraan yang berbahan bakar gas memiliki torsi yang lebih ringgi dari kendaraan berbahan bakar premium. Makin besar torsi , makin besar pula daya yang dihasilkan, sebaliknya makin kecil torsi, makin kecil pula daya yang dihasilkan.

\subsubsection{Data hasil pengujian akselerasi}

Pengujian akselerasi dilakukan dengan menggunakan vericom non contact, dengan pengambilan data pada saat starting acceleration dan passing acceleration ; baik untuk kendaraan menggunakan bahan bakar premium maupun bahan bakar yang menggunakan gas (CNG). Data hasil pengujian termuat pada table berikut :

Table 5.3.Hasil Vericom non Contact test

\begin{tabular}{|c|c|c|c|c|}
\hline \multirow{2}{*}{$\begin{array}{c}\text { Item } \\
\text { Evaluation }\end{array}$} & \multirow{2}{*}{$\begin{array}{l}\text { Posis } \\
\text { i } \\
\text { gear }\end{array}$} & \multirow{2}{*}{$\begin{array}{l}\text { Wak } \\
\text { tu }\end{array}$} & $\begin{array}{c}\text { Premiu } \\
\mathrm{m}\end{array}$ & CNG \\
\hline & & & $\mathrm{m} / \mathrm{s}^{2}$ & $\mathrm{~m} / \mathrm{s}^{2}$ \\
\hline \multicolumn{5}{|c|}{ Starting Acceleration } \\
\hline $0-100 \mathrm{~m}$ & \multirow{3}{*}{$3^{r d}$} & \multirow{3}{*}{$\mathrm{Sec}$} & 7.9 & 8.63 \\
\hline $0-200 m$ & & & 12.19 & 13.34 \\
\hline $0-400 m$ & & & 19.2 & 20.97 \\
\hline $0-40 \mathrm{~km} / \mathrm{h}$ & \multirow{4}{*}{$4^{\text {th }}$} & \multirow{4}{*}{$\mathrm{Sec}$} & 3.07 & 3.74 \\
\hline $0-60 \mathrm{~km} / \mathrm{h}$ & & & 5.49 & 6.84 \\
\hline $0-80 \mathrm{~km} / \mathrm{h}$ & & & 9.2 & 11.85 \\
\hline $0-100 \mathrm{~km} / \mathrm{h}$ & & & 14.41 & 19.47 \\
\hline \multicolumn{5}{|c|}{ Passing Acceleration } \\
\hline $30-60 \mathrm{~km} / \mathrm{h}$ & $3^{\text {rd }}$ & \multirow{4}{*}{$\mathrm{Sec}$} & 6.09 & 8.43 \\
\hline $40-80 \mathrm{~km} / \mathrm{h}$ & $4^{\text {th }}$ & & 13.61 & 18.7 \\
\hline $60-80 \mathrm{~km} / \mathrm{h}$ & $4^{\text {th }}$ & & 7.12 & 9.07 \\
\hline $80-100 \mathrm{~km} / \mathrm{h}$ & $4^{\text {th }}$ & & 7.12 & 10.19 \\
\hline
\end{tabular}

Dari table diatas terlihat bahwa starting acceleration kendaraan uji dengan bahan bakar gas (CNG) pada posisi gigi 1 sampai gigi 3 lebih lambat dibandingkan dengan yang berbahan bakar premium.; starting acceleration antara kendaraan uji berbahan bakar premium dengan

yang berbahan bakar gas gas memiliki perbedaan 1,2 detik. Demikian pula untuk posisi gigi 1 sampai dengan 4, kendaraan uji berbahan bakar gas lebih lambat dibandingkan dengan berbahan bakar premium.Perbedaan terbesar 
yang dihasilkan oleh kendaraan uji terjadi pada saat strating acceleration dari kecepatan $0-100$ $\mathrm{km} / \mathrm{h}$ yaitu mencapai 5.06 detik.

Hasil pengujian saat passing acceleration kendaraan uji berbahan bakar gas pada gigi 3 sampai gigi 4 adalah lebih lambat dari kendaraan uji berbahan bakar premium. Perbedaan terbesar yang dihasilkan pada pengujian passing acceleration adalah pada kecepatan $40-80 \mathrm{~km} / \mathrm{h}$ yaitu mencapai 5.09 detik.

Perhitungan akselerasi dari vericom non contact test pada table 5.3 adalah sebagai berikut :

$\mathrm{a}=\lim \frac{\Delta \mathrm{v}}{\Delta t}=\frac{d^{2} r}{d t^{2}}$

dimana :

$\Delta \mathrm{v}: \mathrm{v}_{2}-\mathrm{v}_{1}(\mathrm{~m} / \mathrm{s})$

a : percepatan/akselerasi $\left(\mathrm{m} / \mathrm{s}^{2}\right)$

$\mathrm{V}_{1}: 40 \mathrm{~km} / \mathrm{h}=11.1 \mathrm{~m} / \mathrm{s}$

$\mathrm{V}_{0}: 0 \mathrm{~km} / \mathrm{h}=0 \mathrm{~m} / \mathrm{s}$

$\mathrm{T}_{1}: 3.07 \mathrm{~s}$

$\mathrm{T}_{0}: 0 \mathrm{~s}$

maka :

$\mathrm{a}=\frac{11.1-0}{3.07-0}=3.62 \mathrm{~m} / \mathrm{s}^{2}$

perhitungan yang sama dilakukan untuk data berikutnya pada table 5.3, dan hasil perhitungan sebagai tertuang dalam table 5.4.

Table 5.4 hasil perhitungan akselerasi secara matematis

\begin{tabular}{|c|c|c|c|c|}
\hline \multirow{2}{*}{$\begin{array}{c}\text { Item } \\
\text { Evaluation }\end{array}$} & \multirow{2}{*}{$\begin{array}{l}\text { Posisi } \\
\text { gear }\end{array}$} & \multirow{2}{*}{$\begin{array}{c}\text { Wak } \\
\text { tu }\end{array}$} & $\begin{array}{c}\text { Premi } \\
\text { um }\end{array}$ & CNG \\
\hline & & & $\begin{array}{c}\left(\mathrm{m} / \mathrm{s}^{2}\right. \\
1\end{array}$ & $\left.\mathrm{~m} / \mathrm{s}^{2}\right)$ \\
\hline \multicolumn{5}{|c|}{ Starting Acceleration } \\
\hline $0-100 \mathrm{~m}$ & \multirow{3}{*}{$\begin{array}{l}1^{\mathrm{st}} \\
\mathrm{s} / \mathrm{d} \\
3^{\mathrm{rd}}\end{array}$} & \multirow{3}{*}{$\mathrm{Sec}$} & 12.66 & $\begin{array}{c}11.5 \\
9\end{array}$ \\
\hline $0-200 \mathrm{~m}$ & & & 16.41 & $\begin{array}{c}14.9 \\
9 \\
\end{array}$ \\
\hline $0-400 \mathrm{~m}$ & & & 20.83 & $\begin{array}{c}19.0 \\
7\end{array}$ \\
\hline $0-40 \mathrm{~km} / \mathrm{h}$ & \multirow{4}{*}{$\begin{array}{l}1^{\text {st }} \\
4^{\text {th }}\end{array}$} & \multirow{4}{*}{$\mathrm{Sec}$} & 3.62 & 2.97 \\
\hline $0-60 \mathrm{~km} / \mathrm{h}$ & & & 3.04 & 2.44 \\
\hline $0-80 \mathrm{~km} / \mathrm{h}$ & & & 2.42 & 1.88 \\
\hline $0-100 \mathrm{~km} / \mathrm{h}$ & & & 1.93 & 1.43 \\
\hline \multicolumn{5}{|c|}{ Passing Acceleration } \\
\hline $30-60 \mathrm{~km} / \mathrm{h}$ & $3^{\text {rd }}$ & \multirow{4}{*}{$\mathrm{Sec}$} & 4.93 & 3.56 \\
\hline $40-80 \mathrm{~km} / \mathrm{h}$ & $4^{\text {th }}$ & & 2.94 & 2.14 \\
\hline $60-80 \mathrm{~km} / \mathrm{h}$ & $4^{\text {th }}$ & & 2.81 & 2.21 \\
\hline $\begin{array}{l}80- \\
100 \text { km/h }\end{array}$ & $4^{\text {th }}$ & & 2.81 & 1.96 \\
\hline
\end{tabular}

Dari hasil perhitungan akselerasi secara matematis untuk kendaraan berbahan bakar gas dan kendaraan berbahan bakar premium, didapat bahwa kendaraan berbahan bakar gas lebih lambat dari kendaraan berbahan bakar premium.

Dengan demikian baik melalui pengujian maupun perhitungan, akselerasi kendaraan yang menggunakan bahan bakar gas lebih lambat dari kendaraan berbahan bakar premium. Hal ini disebabkan karena keterlambatan pasokan bahan bakar gas kedalam ruang bakar yang disebabkan karena system injeksi di intake manifold, sedangkan untuk bahan bakar premium injeksi bahan bakar langsung ke ruang pembakaran.Selain dari itu torsi pada kendaraan berbahan bakar premium lebih besar dari torsi pada kendaraan berbahan bakar gas.Karena akselerasi kendaraan sangat dipengaruhi oleh torsi yang dihasilkan.

\subsection{Pembahasan}

Keunggulan dan kekurangan penggunaan bahan bakar gas (CNG) dibandingkan dengan bahan bakar premium akan dibahas dari sisi kualitas, biaya, suplai dan keselamatan, yang adalah sebagai berikut :

\subsubsection{Kualitas}

Keunggulan bahan bakar premium adalah : nilai oktan bahan bakar gas (93) lebih tinggi dari premium (88), sehingga proses pembakaran berlangsung dengan lebih baik (ruang bakar lebih bersih), saluran pembuangan bersih dan kerja mesin lebih ringan dan mesin akan lebih awet

Kelemahan bahan bakar gas adalah :

- daya yang dihasilkan bahan bakar gas lebih rendah bila dibandingkan dengan premium; ini diakibatkan karena kompresi yang tidak maksimal.

- akselerasi kendaraan lebih rendah bila dibandingkan dengan yang menggunakan premium, ini diakibatkan karena keterlambatan suplai bahan bakar gas kedalam ruang bakar yang disebabkan oleh system injeksi di intake manifold

\subsubsection{Biaya}

Dengan menggunakan bahan bakar gas, maka diperlukan komponen pendukung yaitu converter kit, yang tersedia di pasaran dengan harga yang bervariasi ( Rp. 15,000,000 s/d $20,000,000,-)$ dan yang dianggap terlalu mahal. Namun dengan harga jual bahan bakar gas di pasaran yang lebih murah (Rp. 3,100,- setara premium per liter) maka dalam beberapa bulan 
kedepan sudah dapat menutupi biaya pembelian converter kit

\subsubsection{Suplai Bahan bakar}

Kendaraan yang menggunakan bahan bakar gas dilengkapi dengan switch selector, yang berfungsi mengalihkan system suplai bila bahan bakar gas habis, yaitu dialihkan untuk menggunakan premium.

Kelemahan dalam hal suplai adalah stasiun pengisian bahan bakar gas (SPBG) masih terbatas, sehingga akan mengalami kesulitan dalam pengisian ulang bahan bakar., disamping waktu pengisian dari stasiun pengisian ke tangki gas yang lama bila dibandingkan dengan premium.

\subsubsection{Keselamatan}

- CNG lebih aman, karena tidak akan terbakar bilatekanannya tidak diturunkan dan tidak didinginkan dengan air.

- Tabung untuk tangki BBG/CNG lebih aman VI. Kesimpulan

- Torsi yang dihasilkan kendaraan berbahan bakar gas lebih rendah dari kendaraan berbahan bakar premium, ini disebabkan karena proses kompresi yang kurang sempurna akibat menggunakan blok mesin yang didesain untuk kendaraan berbahan bakar premium.

- Nilai oktan BBG adalah 93, sehingga proses pembakaran terjadi dengan lebih baik

- Akselerasi kendaraan berbahan bakar gas lebih rendah bila dibandingkan dengan kendaraan berbahan bakar premium, ini disebabkan karena suplai bahan bakar ke ruang bakar terlambat.
- Stasiun pengisian bahan bakar gas (SPBG) masih terbatas, bila dibandingkan dengan untuk premium, sehingga menyulitkan konsumen dalam melaksanakan isi ulang BBG.

\section{Saran}

Mesin yang dibuat untuk kendaraan ini sebaiknya hanya menggunakan bahan bakar gas, sehingga mendapatkan daya dan torsi optimal.

\section{PUSTAKA}

[1] Aris Munandar, Wiranto, penggerak Mula Motor Bakar Torak, ITB Edisi ke-4, Bandung, 1988.

[2] ejournal.undip.ac.id/index.php/kapal/articl e/view file/4738/4290 oleh R.S Alam, 2013

[3] Peraturan Gubernur No. 141 Tahun 2007, tentang penggunaan BBG untuk angkutan umum dan kendaraan operasional Pemda,

[4] Permen Perindustrian No. 70/MIND/PER/7/2012, tentang Pemberlakuan Persyaratan Teknis Rangkaian Komponen Konverter Kit untuk Kendaraan Bermotor secara Wajib

[5] Peraturan Presiden RI No. 64 tahun 2012, tentang Penyediaan, Pendistribusian dan Penetapan Harga BBG untuk Transportasi Jalan

[6] Tugaswati, A.T. 2004. Emisi Gas Buang Kendaraan Bermotordan Dampaknya Terhadap Kesehatan

[7] Saft7. April 2011. Emisi Gas Buang Kendaraan Bermotor dan Dampaknya terhadap kesehatan 